\title{
Quality Enhancement of Foundry Products - A Case Study of Foundry Industry of Sri Lanka
}

\author{
R. G. N. De. S. Munasinghe and G.I.P. De Silva \\ University of Moratuwa
}

\begin{abstract}
The foundry industry in Sri Lanka dates back to as far as the second century BC and is still in its developing stage. The quality of foundry cast products manufactured in Sri Lanka is not up to a competent level with the international market. Highly labour intensive methods used, compared to other sectors of the metal working industry, and low productivity can be considered as significant reasons for the less competitiveness. Also, the technological development of this industry is stagnated and it should be improved to a great extent. This deficiency may be due to lack of knowledge in modern technology, unavailability of experts, scarcity of quality raw materials and inadequate new investments. All these factors are also highly influenced by the industrial policies implemented in Sri Lanka. Hence, it is essential to carry out a detailed study on the present situation in Sri Lankan foundries so that appropriate modifications can be implemented to the existing system.
\end{abstract}

The study presented in this paper reveals the present situation of the foundry industry in Sri Lanka, including types of foundry products and the significant defects concerned with. The methodology adopted for this study includes a national survey carried out among the foundry industries in Sri Lanka. This is done by a structured questionnaire survey and interviews carried out with key people in the industry. The data collected from this survey has been analyzed with PC software according to the districts, types of foundries, items produced and the types of defects. In the latter part of this work, further studies will be carried out experimentally to enhance the total quality of the foundry products.

\section{Introduction}

The foundry industry is one of the most essential industries in the development of a particular economy as it is complementary to any metal-processing activity. The foundry industry is mainly divided into two categories as ferrous and non-ferrous castings. Cast iron comes under the ferrous castings and brass, bronze and aluminium are the major components of non-ferrous castings. The modern ferrous industry based on the cupola furnace was developed in Britain during the eighteenth century and imported to Sri Lanka in the latter part of the nineteenth century.

Manuscript received: 16.02 .2005

Revised manuscript received: 04.05.2005

Manuscript accepted: 06.05.2005
A large percentage of foundries in Sri Lanka still use the obsolete and primitive technology and such foundries result in low productivity, wastage of material, low quality of products and unfavourable working conditions. The aim of this work is to investigate the present situation of foundries and identify the essential quality parameters of foundry products.

\section{Methodology}

- A structured questionnaire survey sheet was prepared (Refer Appendix 1) including types of castings produced, types of items produced, total output capacity/year, source of raw materials, employment records, machinery \& equipment and casting defects, etc. 
- 200 foundries were selected for the structured questionnaire survey including all foundry categories located in various areas in Sri Lanka.

- Some of the foundries were visited to get ideas about the technology and quality parameters that they are concerned with.

- The data analysis was done with computer software such as Microsoft Access 2000 \& Microsoft Excel 2000.

\section{Results}

\subsection{Analysis of Responses from the Districts}

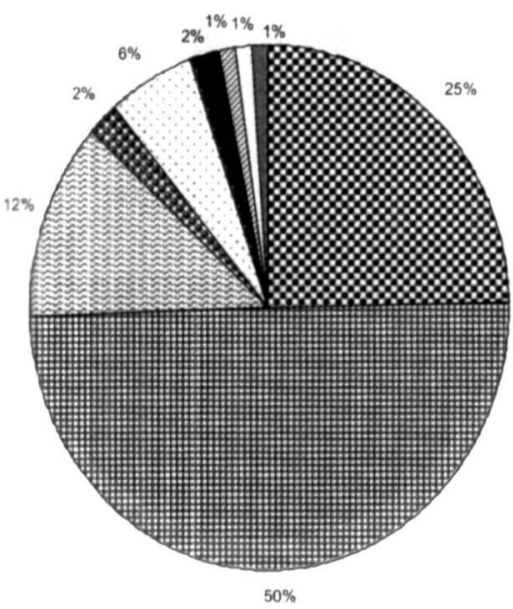

Kandy

由 Colombo

园 Gampaha

Kurunegala

$\square$ Matara

- Galle

圆 Hambantota

$\square$ Kegalle

a Badulla

Figure 1: Analysis of responses of the districts

\subsection{Analysis of Types of Foundries in} Sri Lanka

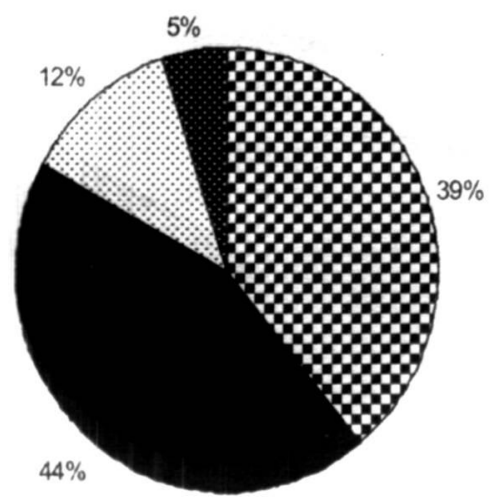

Figure 2: Anaiysis of types of foundries
Brass

Aluminium

을 Iron

Bronze

\subsection{Analysis of Foundry Items Produced} in Sri Lanka

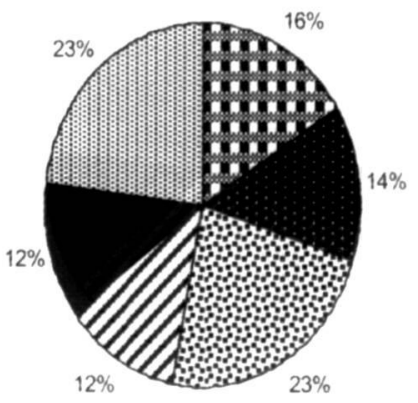

Door \& window fittings

B Kitchen equipment

(t) Omaments

D Automobile parts

- Pump parts

[0] Machinery parts

\subsection{Analysis of Casting Defects of all Types of Foundry Products}

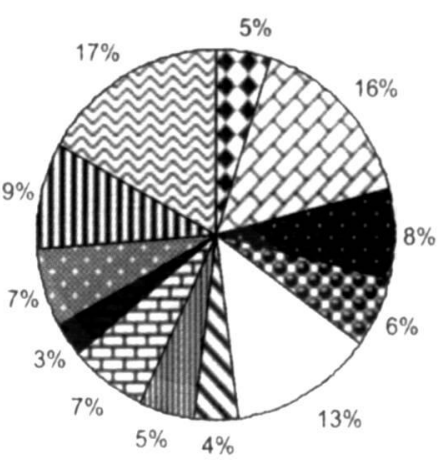

Figure 4: Analysis of casting defects
Shrinkage

Blow holes

- Slag inclusions

Sand inclusions

$\square$ Misrun

$\checkmark$ Swell

m Erosion

口 Shifts

Porosity

口in holes

II Cold shut

घ Cracks

According to Figure 4, cracks and blow holes are the major types of defects.

\subsection{Analysis of moulding sand used in all} types of foundries

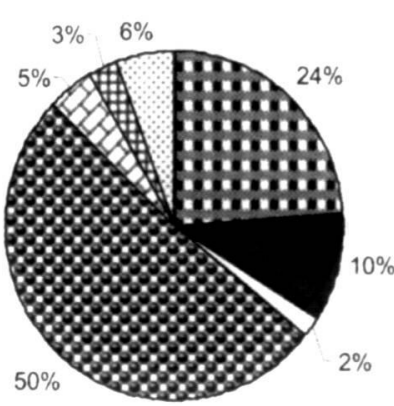

Tile dust \& Granite powder

- Silica sand (local) \& Bentonite

$\square$ Silica sand (Imported) \& Bentonite

Granite powder

Aruwakkaru soil

由 Silica sand (local) \& clay(kirimati)

$\square$ other

Figure 5 : Analysis of moulding sand used 


\subsection{Analysis of the scale of the foundries in Sri Lanka}

The scale of the foundries was decided according to the amount of raw materials used per month

\section{Table 1: Scale of the foundries}

\begin{tabular}{|l|l|}
\hline \multicolumn{1}{|c|}{$\mathbf{k g} /$ month } & Scale of foundry \\
\hline $0-500$ & Very small \\
\hline $500-3000$ & Small \\
\hline $3000-10000$ & Medium \\
\hline more than 10000 & Large \\
\hline
\end{tabular}

\section{Brass foundries}

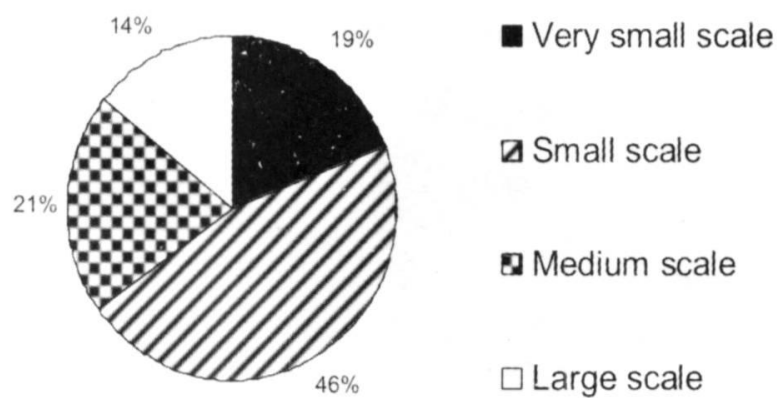

Figure 6: Analysis of the scale of brass foundries

\section{Aluminium foundries}

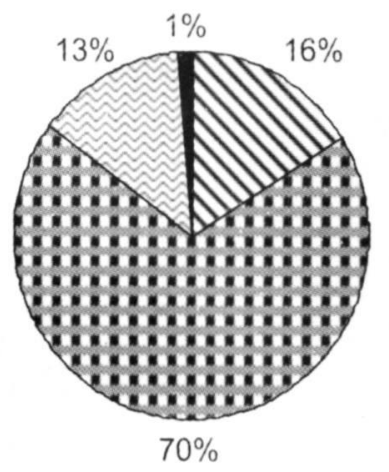

$\otimes$ Very small scale

๑ Small scale

Medium scale

Large scale

Figure 7 : Analysis of the scale of Aluminium foundries

\section{Cast iron foundries}

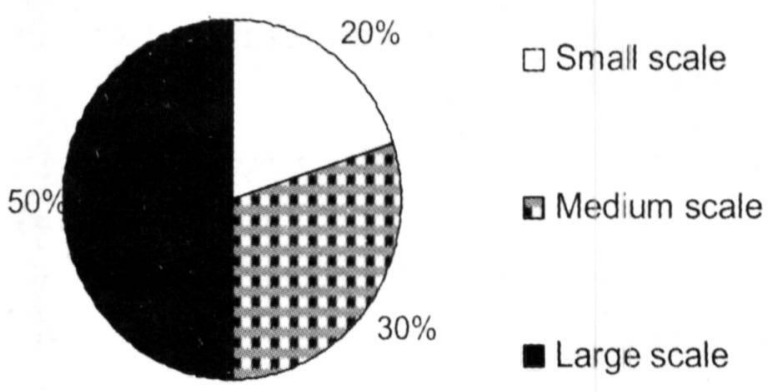

Figure 8: Analysis of the scale of cast iron foundries

\section{Discussion}

The foundry industry has a major role to play in the economic development of our country. Unfortunately in Sri Lanka the technological development of this industry has stagnated. The skill of the foundryman is still considered as a craft gained by years of experience. As a result the methods adopted are very outdated and not scientific except in a very few foundries. Highly labour-intensive methods are less productive when compared with the other sectors of the metal-working industry .

Basically, four major types of foundries can be identified in Sri Lanka which are brass, bronze, aluminium and cast iron. Through the survey it was identified that most of the foundries are scattered in the districts of Kandy, Colombo, Gampaha, Kurunegala, Matara and Hambantota. In the Kandy district most of the foundries are brass foundries and they produce betal trays, kendies, vases and oil lamps. Malambe, Kaduwela, Athurugiriya and Ranala are the regions in the Colombo district where foundries are scattered and they produce aluminium products such as pans, jugs, spare parts for gas cookers, kettles and string hopper machines. Kadawatha,Kelaniya and Kiribathgoda are the regions where foundries are located in the Gampaha district and most of these are aluminium foundries. The foundry industry has existed from generation to generation in above mentioned regions and therefore the traditional technology and skilled 
foundrymen are bonded with these regions. Special types of soils,sands and clays which can be used to prepare suitable moulding sand are located in these regions as natural resources. As an example, granite powder is used as the moulding sand especially in Kiribathgoda, Malambe, Athurugiriya and Kaduwela regions as it is extensively available in these regions. Around 50\% of the foundries are scattered in the Colombo district. The main reasons for this situation are that the products are demanded by a good market and most of the foundries which produce light engineering products for the international market are scattered in the Colombo district. According to fig. 2 most of the foundries in Sri Lanka are aluminium foundries and there are a very little number of bronze foundries. When analyzing the castings produced in Sri Lanka, ornaments and machinery parts form the majority. (fig 3 ). Some of the cast iron products are Brake shoes, Rubbing blocks, Rollers, Bearing blocks and different types of machinery parts.

\subsection{Technology used in local foundries}

A large proportion of castings, especially aluminium castings, are made using granite powder as the moulding sand (fig.5). Unfortunately, the quality of the castings is not of the required level. This deficiency may be due to a lack of knowledge of the properties of moulding sand such as permeability, clay content, green compression strength and AFS (American Foundrymen's Society) sieve number, etc. and the testing methods of these parameters. Normally, very small and small scale brass foundries use a mixture of tile dust and granite powder as a moulding sand. Few foundries (around 10\%) use a mixture of local silica sand and bentonite to gain better quality but the price of bentonite and transport cost are too high for these foundries. Today the necessity of locally available, naturally bonded sand or sand mixture which can give better quality with a low cost is felt strongly by foundrymen in Sri Lanka.
The common method of reconditioning moulding sand is by hand sieving and the use of a mix Muller is rare. In most small foundries the mould boxes are seldom clamped together, but weighted down from the top to avoid thermal expansion [1]. Several medium size foundries use steel moulding boxes with dowel pins and clamps. In addition to the use of moulding boxes, floor moulding is also extensively practiced. The situation of the non ferrous foundries scattered over the country is also far from satisfactory. Also the furnaces used are the oil fired type and the efficiency is not of a satisfactory level as they are designed without theoretical considerations [1]. Electric furnaces are used in large scale foundries like CHICO \& IDB as they produce cast iron products on a large scale.

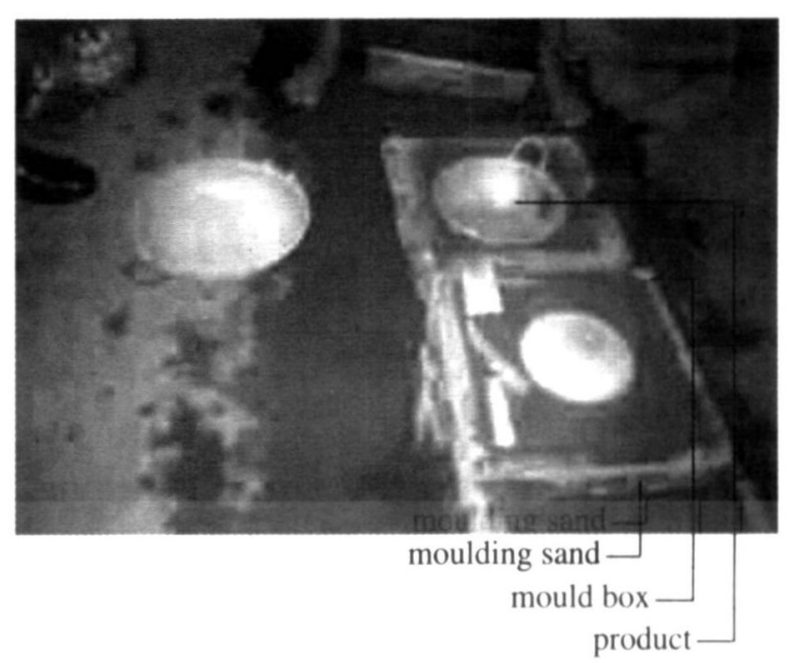

Figure 9: Producing aluminium castings using granite powder as a moulding sand.

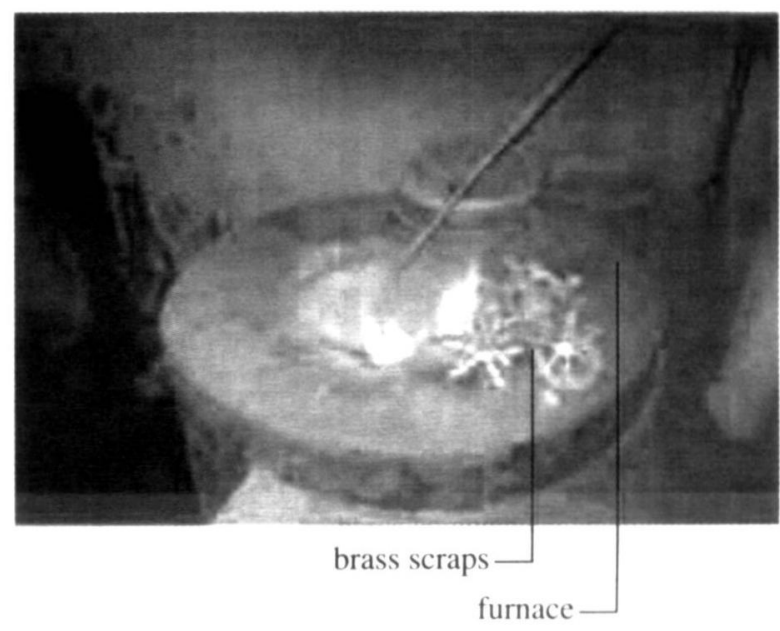

Figure 10: Oil fired type furnace 
In most small foundries the pouring temperature is not measured and is based only on eye estimation. In some cases the temperature comes down during the handling process which causes casting defects. The gating system is prepared on the skill and experience of the foundrymen without any theoretical background. The castings made are kept overnight and removed from the moulds. The foundrymen remove sprues, runner bars, in gates and risers by breaking with hammer blows. In most foundries, they are not cut off by a band saw. The casting fins and other rough surfaces are ground off using angle grinders or in a pedestal grinder. Shot blasting facility is not available in most of the foundries in Sri Lanka. Lack of overall metallurgical control of the casting process has resulted in a very high number of rejects. Quality inspection is mostly only visual. Any form of nondestructive or metallurgical tests are rarely carried out, the quality being often revealed at the machining stage [2].

\subsection{The quality of the castings}

There is an urgent need to enhance the quality of foundry products as it is not up to a competent level with the international market. The quality of a product is closely related to the customer's requirements and quality parameters are dependent on the type of product. As an example, the most significant quality parameter of the castings in ornaments is the surface finish, but in automobile parts and in machinery parts strength $\&$ hardness are the significant quality parameters. Casting defects such as blow holes, slag inclusions, sand inclusions, swell, erosion and cracks affect the surface finish of the castings. Cracks are the major defects in all types of castings (fig 4). The quality of the casting basically depends on the casting process, gating system and the composition of the metal. Normally, in local foundries, door \& window fittings are produced by using the sand casting process, but in India the same products are produced by using the gravity die casting process, which produces a better surface finish relative to the local products. Today the production of brass castings is done by few foundries as the price of the pure $\mathrm{Cu}$ and $\mathrm{Zn}$ ingots is unbearable for the local foundrymen. Therefore most of the foundries use brass scrap, which has a certain amount of other metals such as $\mathrm{Al}, \mathrm{Fe} \& \mathrm{Sn}$ and results in a lower quality of product. In Sri Lanka, some customers pay attention towards the price rather than the quality of product and they are willing to buy products which are imported from India and China.

\subsection{The local \& international demand}

Although mainly catering to the local market it has a high export potential. Local demand is extensively directed towards ornaments and machinery parts. However, the demand for kitchen equipment, door \& window fittings are at a satisfactory level. At present this industry exports a few foundry products and it indirectly contributes to exports by supplying machinery components to industries such as tea and rubber [3].

Studies undertaken in Sri Lanka show that the efficiency and competitiveness of the local light engineering industry is in a satisfactory level relative to the international level. The country exports products such as precision tools, moulds and electrical enclosures and manufactures high quality water pumps and agricultural machinery for the local market.

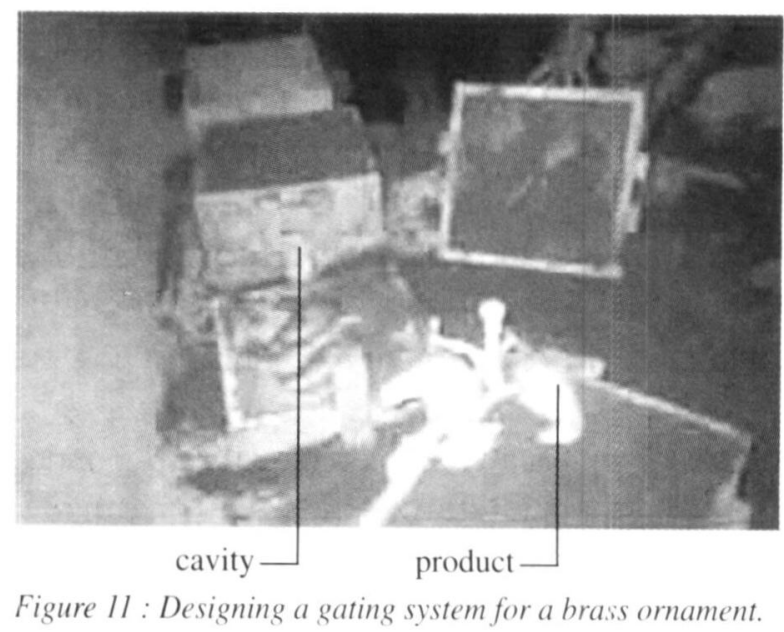


Table:2 Exports of Foundry/Engineering Products for Sri Lanka (Value in Rs.Mn.)

\begin{tabular}{|l|c|c|c|r|}
\hline & 2000 & 2001 & 2002 & \multicolumn{1}{|c|}{2003} \\
\hline Iron \& steel products & 817.35 & 784.76 & 1368.18 & 1011.3 \\
\hline Copper products & 112.48 & 301.2 & 6380.82 & 11568.68 \\
\hline Lead products & 250.39 & 110.63 & 314.08 & 285.6 \\
\hline Tools \& Equipments & 7.69 & 39.52 & 119.29 & 31.17 \\
\hline Others & 72.57 & 99.25 & 79.91 & 356.13 \\
\hline Total & 1885.12 & 1912.42 & 9196.87 & 14145.05 \\
\hline
\end{tabular}

Source: Sri Lanka Customs

\subsection{The involvement of the government \& the private sector}

Sri Lanka's current industrial policy is based on the experience of other well performing Asian Economies. The government seeks to provide a 'stable and sustainable' macro economic environment, which will tend to accelerate industrial development.

The recently presented budget for year 2005 , mentioned about the foundry industry as follows,

"Access of $25 \%$ will be imposed on export of ferrous and non ferrous in the form of scrap or any other form based on London Exchange Metal Price in order to ensure continuous supply of raw material required by the local industry. The expected income of Rs. 120 million from this cess will be utilized for upgrading technical skills and improving the productivity of the foundry industry" [4].

By implementing this proposal the scarcity of ferrous \& non ferrous scrap, which is the major problem that the foundry industry faces today could be minimized. The fundamental problem of the foundry industry can be identified as the lack of training of persons at all levels, dearth of metallurgists and lack of investments. The Ministry of Small \& Rural Industries, Board of Investment (BOI) \& the Export Development Board (EDB) are the principal government agencies responsible for industrial activities in Sri Lanka. Hence, they can implement a proper procedure to solve the above mentioned fundamental problems. Workshops could be organized as a part of this procedure with the support of universities. Institutions such as the Universities, Industrial Technological Institute (ITI) and National Engineering Research \& Development Centre can play a predominant role in promoting the technology used in foundries. Especially, research can be done to enhance the efficiency of the melting process. The higher price of coke, furnace oil and gas is one of the major problems that the foundry industry faces today and the involvement of government to solve this problem is essential. The Foundry Development \& Services Institute (FDSI) has been established and is managed by the private sector foundry industry in Sri Lanka. The FDSI efforts are aimed at improving the productivity; quality and the market share of the foundry sub-sector and upgrading the foundry industry so that castings to international specifications could be produced. Although the membership of FDSI is more than $\mathbf{5 0}$ companies, at present there are only about 25 companies that regularly participate at meetings[3].

The recent changes in the economic scenario and progressive government policies can make a great impact on the Sri Lankan foundry industry. As a result of the government's reform policy and the classification of the foundry industry as a thrust industry it is obvious that both the government and the 
private sector of the country should involve themselves by directly implementing positive actions to upsurge the enthusiasm in local foundrymen to develop the foundry industry.

\section{Conclusions}

- Most of the casting defects that appear in local foundry products affect the surface finish. Therefore, surface finish was identified as the most significant quality parameter.

- Most of the foundries, specially aluminium foundries, are scattered in the Colombo district.

- The predominant type of foundry in Sri Lanka is the aluminium foundry.

- Most of the foundries produce ornaments and machinery parts.

- Cracks and blow holes are the major types of defects in castings produced in Sri Lanka.

- Granite powder is the extensively used moulding sand in local foundries

- Most of the brass and aluminium foundries are small scale foundries and a few large scale cast iron foundries are scattered in the Colombo district.

\section{Acknowledgements}

The national foundry survey has been successfully completed due to the help of many interested institutes and individuals and this opportunity is taken to thank all of them who assisted to make this task a success. We are most grateful to the Ministry of Enterprise Development, Industrial Development Board (IDB) Katubedda, Peliyagoda, and Pilimathalawa and Foundry Development \& Services Institute (FDSI) for their support and guidance during every phase of our survey.

We would like to take this opportunity to offer our deepest gratitude to Dr. S.U. Adikary, the
Head of the Department of Materials Engineering. Then, we like to place on record our appreciation to Mr. S.P. Guluwita who always encouraged us by providing his fullest co-oporation to identify the locations of foundries. Again, it is a pleasure to thank Mr. Nimal Premathileka, President of the Foundrymen's Society of Kiribathgoda \& $\mathrm{Mr}$ H. Premadasa, President of the Foundrymen's Society of Malembe for devoting their precious time to provide required details about foundries in their areas.

Thanks too are extended to Mr. R. Karunathileke who helped us by taking photographs of the foundries. Finally, we would like to express our thanks to Mrs. Chandani, the previous research assistant of the Department of Materials Engineering, for her invaluable guidance and advice to carry out the survey successfully.

\section{References}

(1) Tittagala S.R., Welding, Casting $\&$ Metal Forming Country Report-Sri Lanka University of Moratuwa , Moratuwa, 1990

(2) Fernando B.S.N., Foundry Industry In Sri Lanka. Country Report, Industrial Development Board (IDB), 1999

(3) http://www.Srilankabusiness.com/tradeinfo/Srilanka

(4) http://www.treasury.gov.lk

\section{Biographical Sketches}

DR. R. G. N. DE. S. MUNASINGHE, MSc (Berlin), PhD (Berlin), Director/ Postgraduate Studies, Faculty of Engineering, Senior Lecturer, Department of Materials Engineering University of Moratuwa, Sri Lanka

G.I.P. DE SILVA, BSc Eng, MPhil student at Department of Materials Engineering, University of Moratuwa, Sri Lanka 


\title{
SURVEY ON FOUNDRY INDUSTRIES IN SRI LANKA

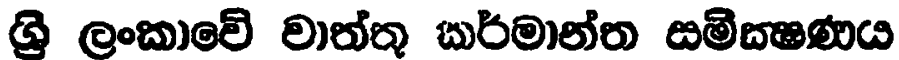

\author{
Conducted by Departinent of Materials Engineering \\ University of Moratuwa

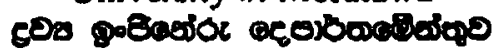

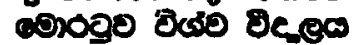

1. Details of the Foundry

\section{orda woodiow egees 8doo}

1.1 Name of the Foundry/Industry :

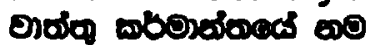

1.2 Address

EBoxs

1.3 Telephone No.

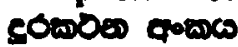

1.4 Name of the person to contact : crobico gas qasocs 000

1.5 Designation

-

2 Products

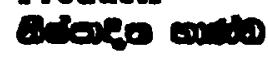

2.1 Types of Castings Produced (Please tick the appropriate box(es)\}

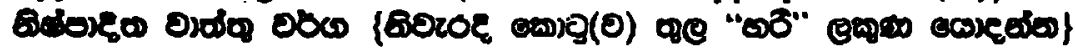

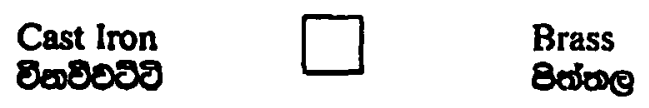

\begin{tabular}{|c|}
\hline $\begin{array}{l}\text { Bronze } \\
\text { colpod }\end{array}$ \\
\hline
\end{tabular}

Others

coos.

Please specify

00 modio

2.2 Items Produced (Please tick the appropriate box(es)\}

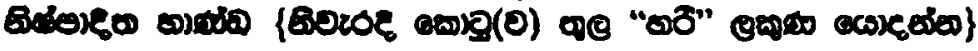

Machinery parts $\square$ Omaments

costo

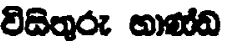

Pump parts

cosiso 00 and

Kitchen equipment Q000resocos cososo

Automobile parts

Door \& window fittings

Oxeser De बandos

oco ocoso cosoco

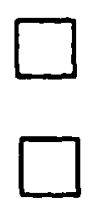


2.3 Total output capacity/year (approx.)[in inetric tons]

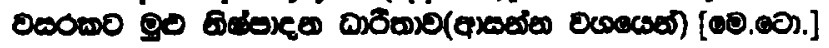

3

\section{Raw materials \\ Q}

3.1 Source of raw materials \{Pleasc tick the appropriate box(es)\}

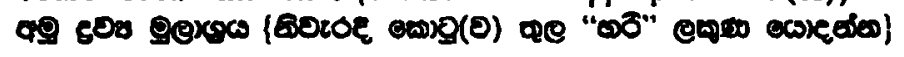
Imported
$\square$ Local

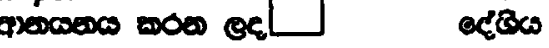
Scrap
ejed argos

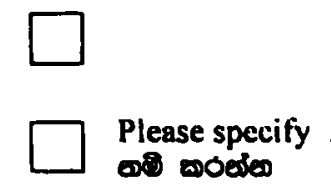

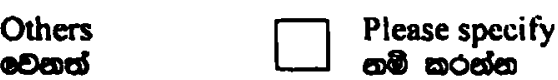

3.2 Types of Raw Materials use (eg. Iron, coke, sand, etc.)

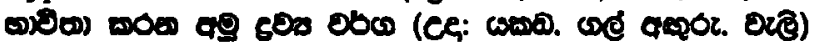

Raw Material Total requirement/year[kg] Source

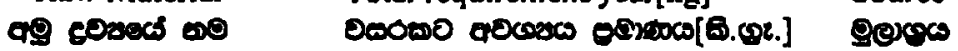

3.3 Are you satisfied with the availability of raw materials in Sri Lanka?

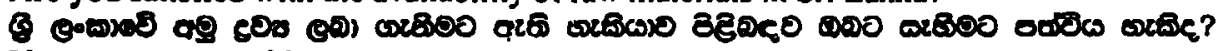
Yes $\square \quad$ No $\square$

If not, Why?

$8 B 0000000$ o 026 ?

4 Employment

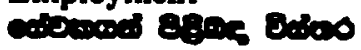

4.1 Total number of Employees

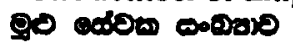


4.2 (a) No. of Skilled Employees 9096000000000

(b) No. of Semi-skilled Employecs Q60 99

(c) No. of Unskilled Employees

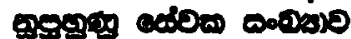

4.3 Do you offer training for your employees?

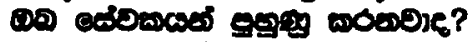

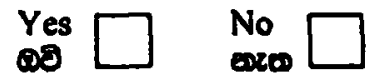

4.3.1 If yes, please give details.

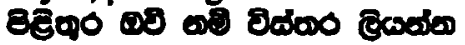

4.3.2 If not, do you need to train your employees?

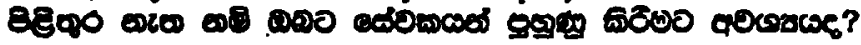

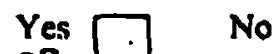

DO

enron

5 Machinery and Equipment \{Please tick the appropriate box(es)\}

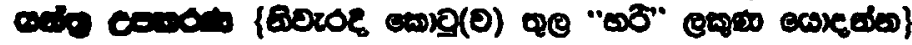

Cupola fumace

Bogeriex

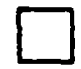

Electric arc furnace

oteod ostom ceso

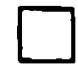

Cleaning equipment Bss. abso conoto

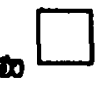

Others

Deod

Please specify

00 acoses
Crucible fumace cerfo obos co

Grinding machine

0600

Sand mixer

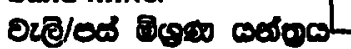

5.1 Is the available machines fully utilized at present? Yes

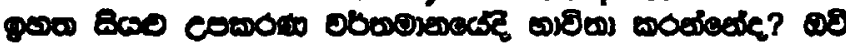

No

If not, please indicate why?

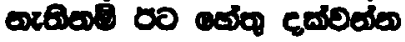

\section{Casting Defects}

$$
\text { encas as }
$$

6.1 Do you come across any defects in castings?

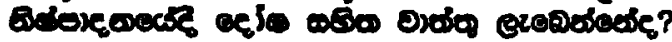

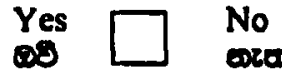

oreo 
6.2 If yes, please indicate the types of defects \{Please tick the appropriate box(es)\}

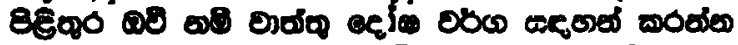

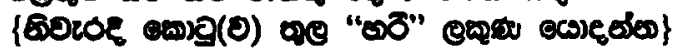

Blow holes

O) \&ezor

Shitts

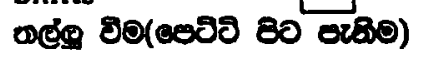

Slag inclusions

Porosity

000000000

D800 D0

Sand inclusions

Ore 900080

Pin holes

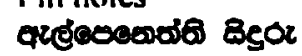

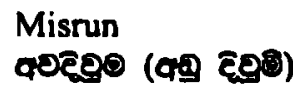

Cold shut/lap

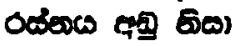

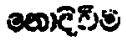

Swell

D200(8050)

Cracl::s

ove (क)

Erosion

बiscoso(ore cosicos)

Shrinkage:

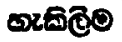

Others

Dewos

Please specify

000000

6.3 Total percentage of rejects due to defective castings

$\%$

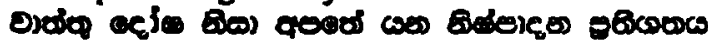

7 Do you get any help or advise from the Ministry of Enterprise Development, Industrial Policy \& Investment Promotion or the Industrial Development Board (IDB)?

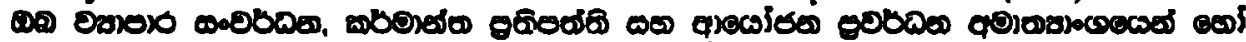

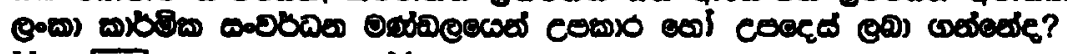

$\begin{array}{ll}\text { Yes } \square & \text { No } \square \\ \text { (1) }\end{array}$

8 How does the Industrial Policy of Sri Lanka affect your foundry? (Please use a separate sheet)

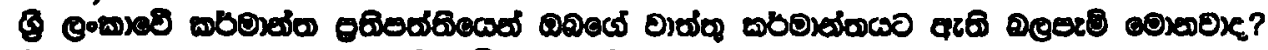

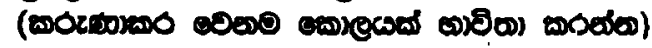

9 Can we visit your Foundry/Industry?

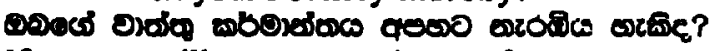

If yes, we will contact you in near future.

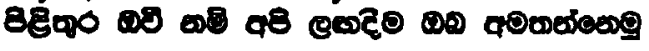

We sincerely thank you for your co-operation.

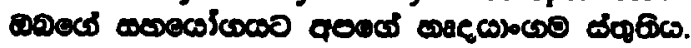

N.B. If space is insufficient, please use a separate sheet.

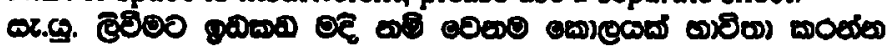

